From the Herbert Irving Comprehensive Cancer Center, Department of Biostatistics, Mailman School of Public Health, Columbia University, College of Physicians and Surgeons, The New York Presbyterian Hospital, Columbia University Medical Center; and Department of Medicine, Lymphoma Service, Department of Radiology, Molecular Pharmacology and Chemistry Program, Department of Clinical Chemistry, Memorial Sloan-Kettering Cancer Center, New York, NY; Research Projections, Phoenixville, PA; and Allos Therapeutics, Westminster, CO.

Submitted October 31, 2008; accepted March 19, 2009; published online ahead of print at www.jco.org on August 3, 2009.

Authors' disclosures of potential conflicts of interest and author contributions are found at the end of this article.

Clinical Trials repository link available on JCO.org.

Corresponding author: Owen A O'Connor, MD, PhD, Lymphoid Development and Malignancy Program, Lymphoma Service, Columbia University, Herbert Irving Comprehensive

Cancer Center, 1130 St Nicholas Ave, Rm 216, New York, NY 10032; e-mail: oo2130@columbia.edu.

C 2009 by American Society of Clinical Oncology

0732-183X/09/2726-4357/\$20.00

DOI: $10.1200 / J C O .2008 .20 .8470$

\title{
Phase II-I-II Study of Two Different Doses and Schedules of Pralatrexate, a High-Affinity Substrate for the Reduced Folate Carrier, in Patients With Relapsed or Refractory Lymphoma Reveals Marked Activity in T-Cell Malignancies
}

Owen A. O'Connor, Steven Horwitz, Paul Hamlin, Carol Portlock, Craig H. Moskowitz, Debra Sarasohn, Ellen Neylon, Jill Mastrella, Rachel Hamelers, Barbara MacGregor-Cortelli, Molly Patterson, Venkatraman E. Seshan, Frank Sirotnak, Martin Fleisher, Diane R. Mould, Mike Saunders, and Andrew D. Zelenetz

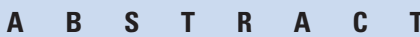

\section{Purpose}

To determine the maximum-tolerated dose (MTD) and efficacy of pralatrexate in patients with lymphoma.

\section{Patients and Methods}

Pralatrexate, initially given at a dose of $135 \mathrm{mg} / \mathrm{m}^{2}$ on an every-other-week basis, was associated with stomatitis. A redesigned, weekly phase I/II study established an MTD of $30 \mathrm{mg} / \mathrm{m}^{2}$ weekly for six weeks every 7 weeks. Patients were required to have relapsed/refractory disease, an absolute neutrophil greater than $1,000 / \mu \mathrm{L}$, and a platelet count greater than $50,000 / \mu \mathrm{L}$ for the first dose of any cycle.

\section{Results}

The every-other-week, phase II experience was associated with an increased risk of stomatitis and hematologic toxicity. On a weekly schedule, the MTD was $30 \mathrm{mg} / \mathrm{m}^{2}$ weekly for 6 weeks every 7 weeks. This schedule modification resulted in a $50 \%$ reduction in the major hematologic toxicities and abrogation of the grades 3 to 4 stomatitis. Stomatitis was associated with elevated homocysteine and methylmalonic acid, which were reduced by folate and vitamin B12 supplementation. Of 48 assessable patients, the overall response rate was $31 \%$ (26\% by intention to treat), including $17 \%$ who experienced complete remission (CR). When analyzed by lineage, the overall response rates were $10 \%$ and $54 \%$ in patients with B- and T-cell lymphomas, respectively. All eight patients who experienced CR had T-cell lymphoma, and four of the six patients with a partial remission were positron emission tomography negative. The duration of responses ranged from 3 to 26 months.

\section{Conclusion}

Pralatrexate has significant single-agent activity in patients with relapsed/refractory T-cell lymphoma.

J Clin Oncol 27:4357-4364. (c) 2009 by American Society of Clinical Oncology

\section{INTRODUCTION}

Pralatrexate is a 10-deazaaminopterin that is structurally similar to methotrexate (MTX). Unlike other antifols, praltrexate was not designed to be a better substrate for folypolyglutamyl synthetase (FPGS) or dihydrofolate reductase. It was rationally designed to have greater affinity for the reduced folate carrier (RFC). This allows the drug to be selectively accumulated in tumor cells. RFC expression is induced by various oncogenes, including $\mathrm{H}$-ras and c-myc, which results in an increase in the rate of internalization of radiolabeled antifol. ${ }^{1}$
RFC is a fetal oncoprotein that is highly expressed on fetal and malignant tissue, and it is the principal transporter through which folates and antifolates enter the cell. ${ }^{1-3}$ The high-level expression is related to the demands for natural folates required by proliferative tissues to synthesize DNA. Biochemically, the influx $\mathrm{V}_{\max } / \mathrm{K}_{\mathrm{m}}$ mediated by RFC shows that pralatrexate is incorporated at a rate 14 times greater than MTX. ${ }^{4-8}$ Similarly, the $\mathrm{V}_{\text {max }} / \mathrm{K}_{\mathrm{m}}$ for the FPGS suggest that pralatrexate is 10 times more efficiently polyglutamylated compared with MTX. ${ }^{4-8}$ This biochemistry suggests that pralatrexate should be more potent than MTX and could overcome 
known mechanisms of MTX resistance in which downregulation of RFC and/or FPGS leads to MTX resistance.

Preclinical models of lymphoma consistently demonstrate superiority for pralatrexate compared with MTX, and most lymphoma cytotoxicity assays demonstrate at least a 1-log lower 50\% inhibitory concentration for pralatrexate. This pattern of activity was observed in B- and T-cell lymphomas, both in vitro and in vivo. ${ }^{9,10}$ Recent studies have established that pralatrexate synergizes with gemcitabine and that this synergy is superior to traditional MTX plus cytarabine. ${ }^{10}$

With this rationale, a phase II study of pralatrexate $\left(135 \mathrm{mg} / \mathrm{m}^{2}\right.$ every other week [QOW]) was initiated in patients with relapsed/ refractory lymphoma. This phase II study, which used the maximumtolerated dose (MTD) identified in patients with non-small-cell lung cancer, ${ }^{11,12}$ revealed a higher incidence of stomatitis in patients with lymphoma. The early experience in patients with lymphoma revealed that the risk of stomatitis was greatest in patients with markedly elevated homocysteine (Hcy) and methylmalonic acid (MMA) levels and in patients with low pralatrexate clearance (high area under the curve exposure). These observations led to a new dose and schedule and to a requirement for folate and vitamin B12 pretreatment. A weekly phase I study was initiated with $30 \mathrm{mg} / \mathrm{m}^{2}$ weekly for 3 of 4 weeks followed by a second phase II trial at the once weekly (QW) MTD of $30 \mathrm{mg} / \mathrm{m}^{2}$ for 6 of 7 weeks (Fig 1). We report here the experience with pralatrexate on these phase I and II studies in patients with non-Hodgkin's lymphoma (NHL) and Hodgkin's lymphoma (HL).

\section{PATIENTS AND METHODS}

\section{Patient Selection}

Patients were required to have histologically confirmed NHL by using the WHO classification or to have HL. Eligibility required the following: measurable disease in the phase II study and evaluable disease in the phase I

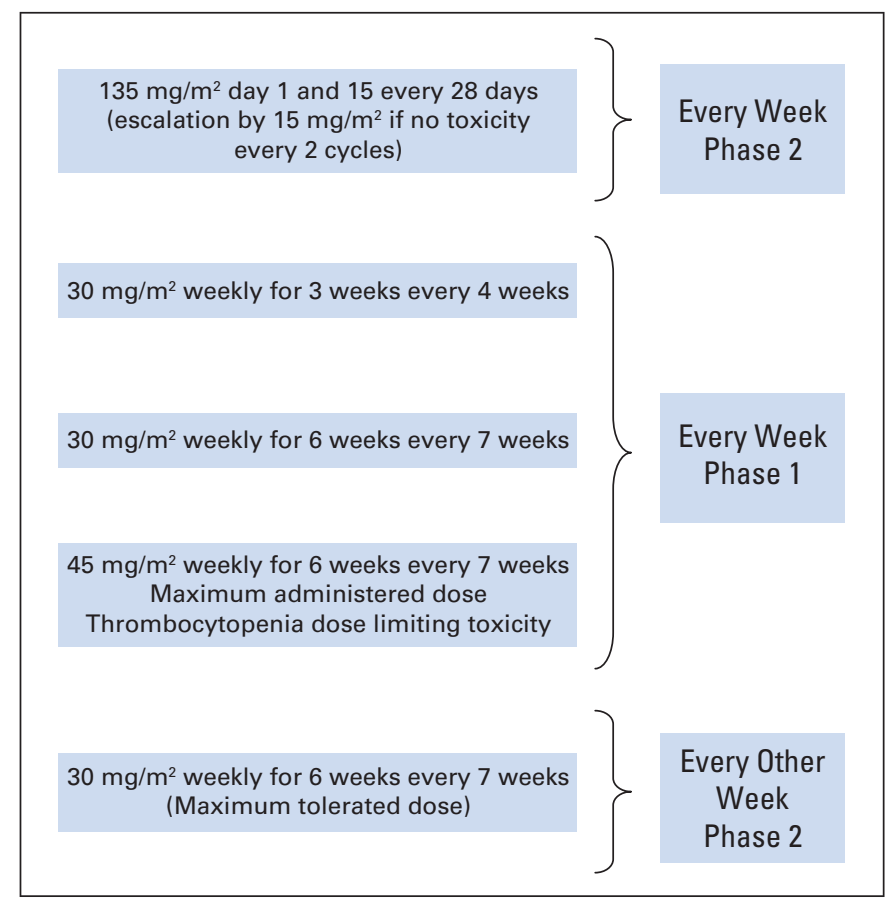

Fig 1. Development of pralatrexate phase II-I-I studies in lymphoma. study; disease that was relapsed/refractory to prior therapy with no limit on prior therapy; no prior chemotherapy for at least 4 weeks; time period of at least 3 months since the last administration of any monoclonal antibody, unless there was objective evidence of disease progression within that time (phase II studies only); 18 years of age or older; life expectancy of 3 months or greater; a Karnofsky performance status $\geq 60 \%$; and no signs of congestive heart failure. Patients were not excluded for febrile episodes as long as there was no evidence of active infection. Prior MTX exposure was not exclusionary. All patients were required to sign an institutional review board-approved informed consent and Health Insurance Portability and Accountability Act consent.

Within 2 days of study drug administration, patients had to meet the following criteria: absolute neutrophil count greater than $1,000 / \mu \mathrm{L}$; platelet count $\geq 50,000 / \mu \mathrm{L}$; total bilirubin $\leq 1.5$ times upper institutional limit of normal (ULN); AST/ALT $\leq 2.5$ times ULN (or four times ULN if liver involvement); and creatinine less than 1.5 times ULN or a creatinine clearance of $\geq 50 \mathrm{~mL} / \mathrm{min}$. Patients were excluded if they were pregnant; had evidence of intracranial disease; had major surgery within 4 weeks; had uncontrolled illness, including active infection, symptomatic congestive heart failure, uncontrolled hypertension, unstable angina pectoris, cardiac arrhythmia, a myocardial infarction, or cerebrovascular accident within 6 months of study enrollment; known HIV disease; or psychiatric illness/social situations that would limit compliance with study requirements.

\section{Study Design}

This was a single-agent Phase II-I-II study of pralatrexate in patients with relapsed or refractory NHL or HL. The objectives of the phase II studies were to determine the frequency and duration of complete remission (CR) and partial remission (PR), and the objectives of the phase I study were to determine the MTD and dose-limiting toxicities (DLTs) of weekly pralatrexate.

During the QOW phase II study, all patients began pralatrexate treatment at $135 \mathrm{mg} / \mathrm{m}^{2}$. Patients who tolerated this dose were eligible for dose escalation (by $15 \mathrm{mg} / \mathrm{m}^{2}$ until toxicity occurred). All patients had full pharmacokinetic (PK) studies with pre- and post- treatment Hcy, MMA, vitamin B12, and intraerythrocytic folate levels.

During the phase I study, dose escalation employed a modified Fibonacci schema that started at $30 \mathrm{mg} / \mathrm{m}^{2}$ weekly for 3 of 4 weeks. Three new patients per cohort were treated and observed for at least 7 weeks before opening the next dose cohort. At each new dose, patients were enrolled until the first DLT, defined as grades 3 or 4 nonhematologic toxicity (excluding alopecia and infusion site reactions); nausea, vomiting, or diarrhea that persists beyond 10 days of dosing uncontrolled by aggressive treatments; grade 3 febrile neutropenia or grade 4 neutropenia that preempts administration of the next dose; grade 4 thrombocytopenia; and any toxicity not defined as a DLT that lasts 3 weeks. In addition, DLT was not met when any patient missed more than a third of the doses in cycle 1 .

Three patients per dose cohort were enrolled simultaneously, and escalation was as follows: twice the dose of $15 \mathrm{mg} / \mathrm{m}^{2}$, triple the dose of $15 \mathrm{mg} / \mathrm{m}^{2}$, four times the dose of $15 \mathrm{mg} / \mathrm{m}^{2}$, and continued similar increases with no upper limit. If one patient experienced a DLT, three additional patients were added. If two of six patients experienced a DLT during the first cycle of therapy, this dose level was declared the maximum administered dose (MAD), and the previous dose level was declared the MTD. When the MAD was defined, there was no additional dose escalation. An additional 20 to 30 patients were allowed to be treated at the QW MTD.

\section{Drug Administration}

Pralatrexate was supplied as the free acid in a dry powder. Weighed portions of the drug were suspended in bacteriostatic sterile normal saline USP adjusted to $\mathrm{pH}$ 7. The final concentration was $10 \mathrm{mg} / \mathrm{mL}$. Formulation and vialing of pralatrexate were performed by the institutional Research Pharmacy (Memorial Sloan-Kettering, New York, NY) for the QOW phase II study; thereafter, pralatrexate was supplied by Allos Therapeutics (Westminster, $\mathrm{CO}$ ). The drug was administered intravenously by bolus injection (over 3 to 5 minutes) with normal saline.

\section{Dose Modification}

In the Phase II QOW study, dose modifications were based on the grade of stomatitis. If a patient failed to meet the criteria for re-treatment, then 


\begin{tabular}{|c|c|c|c|c|c|c|}
\hline \multirow[b]{3}{*}{ Parameter } & \multicolumn{6}{|c|}{ Study Phase and Design } \\
\hline & \multicolumn{2}{|c|}{ Phase II QOW ( $n=16)$} & \multicolumn{2}{|c|}{ Phase I OW $(n=17)$} & \multicolumn{2}{|c|}{ Phase II OW $(n=24)$} \\
\hline & No. & $\%$ & No. & $\%$ & No. & $\%$ \\
\hline \multicolumn{7}{|l|}{ Age, years } \\
\hline Median & \multicolumn{2}{|c|}{55} & \multicolumn{2}{|c|}{53} & \multicolumn{2}{|c|}{59} \\
\hline Range & \multicolumn{2}{|c|}{$29-78$} & \multicolumn{2}{|c|}{$23-75$} & \multicolumn{2}{|c|}{$38-80$} \\
\hline \multicolumn{7}{|l|}{ Sex } \\
\hline Male & 12 & 75 & 6 & 35 & 16 & 65 \\
\hline Female & 4 & 25 & 11 & 65 & 8 & 33 \\
\hline \multicolumn{7}{|l|}{ Ethnicity } \\
\hline White non-Hispanic & 10 & 63 & 7 & 41 & 19 & 79 \\
\hline White Hispanic & 3 & 19 & 1 & 6 & 0 & 0 \\
\hline Black non-Hispanic & 2 & 13 & 3 & 18 & 3 & 13 \\
\hline Asian/Indian & 1 & 6 & 1 & 6 & 0 & 0 \\
\hline Asian/Pacific Islander & 0 & 0 & 3 & 18 & 2 & 9 \\
\hline Other & 0 & 0 & 2 & 12 & 0 & 0 \\
\hline \multicolumn{7}{|l|}{ Disease } \\
\hline DLBCL & 8 & 50 & 3 & 18 & 2 & 8 \\
\hline Hodgkin's lymphoma & 5 & 31 & 3 & 18 & 0 & 0 \\
\hline T cell & 1 & 6 & 11 & 65 & 18 & 75 \\
\hline Mantle cell/CLL & 2 & 13 & 0 & 0 & 1 & 4 \\
\hline Follicular & 0 & 0 & 0 & 0 & 1 & 4 \\
\hline Composite lymphomas* & 0 & 0 & 0 & 0 & 2 & 8 \\
\hline \multicolumn{7}{|l|}{ Prior therapy } \\
\hline CHOP/RCHOP/NHL-15/CHOEP & 11 & 69 & 8 & 47 & 14 & 58 \\
\hline CVP \pm rituximab/ontac/CEPP & 1 & 6 & 0 & 0 & 0 & 0 \\
\hline ICE/RICE & 11 & 69 & 6 & 35 & 6 & 25 \\
\hline DHAP/ESHAP \pm rituximab & 5 & 31 & 2 & 12 & 3 & 13 \\
\hline $\mathrm{HDC}+\mathrm{ASCT}$ & 4 & 25 & 5 & 29 & 2 & 8 \\
\hline HyperCVAD/EPOCH & 1 & 6 & 3 & 18 & 6 & 25 \\
\hline DVIP/MINE & 1 & 6 & 0 & 0 & 1 & 4 \\
\hline ALL-2/L-20 & 0 & 0 & 1 & 6 & 1 & 4 \\
\hline Vinblastine & 1 & 6 & 1 & 6 & 0 & 0 \\
\hline Fludarabine & 0 & 0 & 0 & 0 & 1 & 4 \\
\hline Pentostatin & 0 & 0 & 2 & 12 & 2 & 8 \\
\hline Gem/fludarabine/cisplatin & 1 & 6 & 0 & 0 & 0 & 0 \\
\hline ABVD/MOPP/ABVD-MOPP (COPP) & 5 & 31 & 2 & 12 & 0 & 0 \\
\hline Stanford V & 0 & 0 & 1 & 6 & 0 & 0 \\
\hline Gem/GND/Gem $n \pm$ rituximab & 3 & 19 & 4 & 24 & 1 & 4 \\
\hline Rituximab & 4 & 25 & 2 & 12 & 3 & 13 \\
\hline Bexarotene & 0 & 0 & 1 & 6 & 2 & 8 \\
\hline Alemtuzimab & 1 & 6 & 1 & 6 & 3 & 13 \\
\hline MDX-60 & 0 & 0 & 2 & 12 & 0 & 0 \\
\hline Dennilieukin difitox & 0 & 0 & 1 & 6 & 3 & 13 \\
\hline HDACI SAHA or depsipeptide & 4 & 25 & 1 & 6 & 0 & 0 \\
\hline Carfilzomib proteasome inhibitor & 0 & 0 & 0 & 0 & 2 & 8 \\
\hline Cyclosporin \pm corticosteroids & 0 & 0 & 2 & 12 & 4 & 17 \\
\hline Radiation & 7 & 44 & 4 & 24 & 1 & 4 \\
\hline \multicolumn{7}{|c|}{ 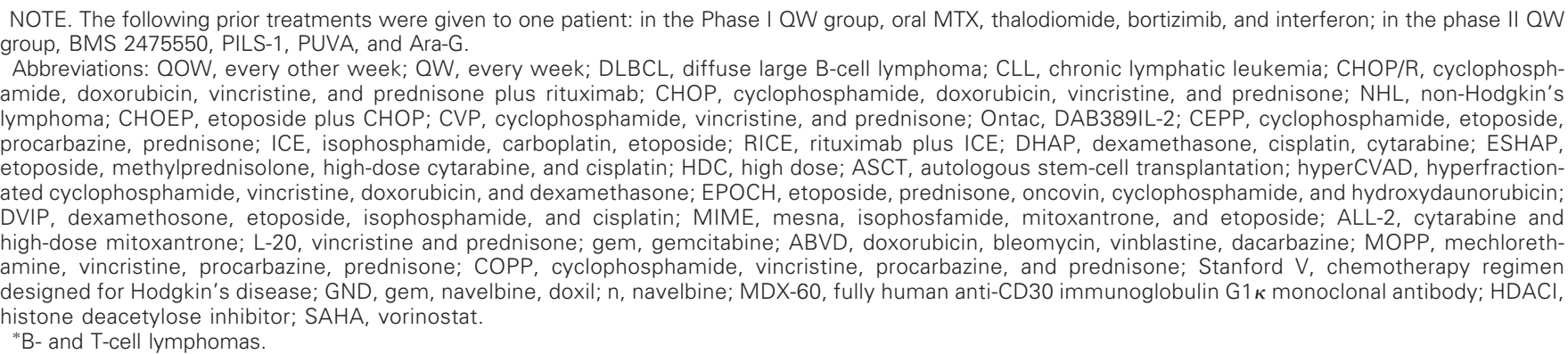 } \\
\hline
\end{tabular}


treatment was delayed for 1 week. Dose escalation was allowed after the patient received two cycles of pralatrexate with no toxicities. Dose modifications for stomatitis were as follows by grade of stomatitis: If no toxicity (grade 0 stomatitis) was observed after two cycles, the dose was escalated to $150 \mathrm{mg} / \mathrm{m}^{2}$ for two cycles (ie, 4 weeks). If no stomatitis was noted after two additional cycles, escalation in $15-\mathrm{mg} / \mathrm{m}^{2}$ increments was allowed indefinitely. If any patient developed grades 1 or 2 stomatitis during cycle 1 or 2 , the patient received folate ( $5 \mathrm{mg}$ orally each day beginning 3 days before pralatrexate administration and continuing to the day of and the day after pralatrexate administration) and vitamin B12 (1,000 $\mu$ g orally each day or $100 \mathrm{mcg}$ intramuscularly every 8 to 9 weeks). Continued grades 1 or 2 stomatitis could result in a dose reduction at the discretion of the principal investigator. Any patient who

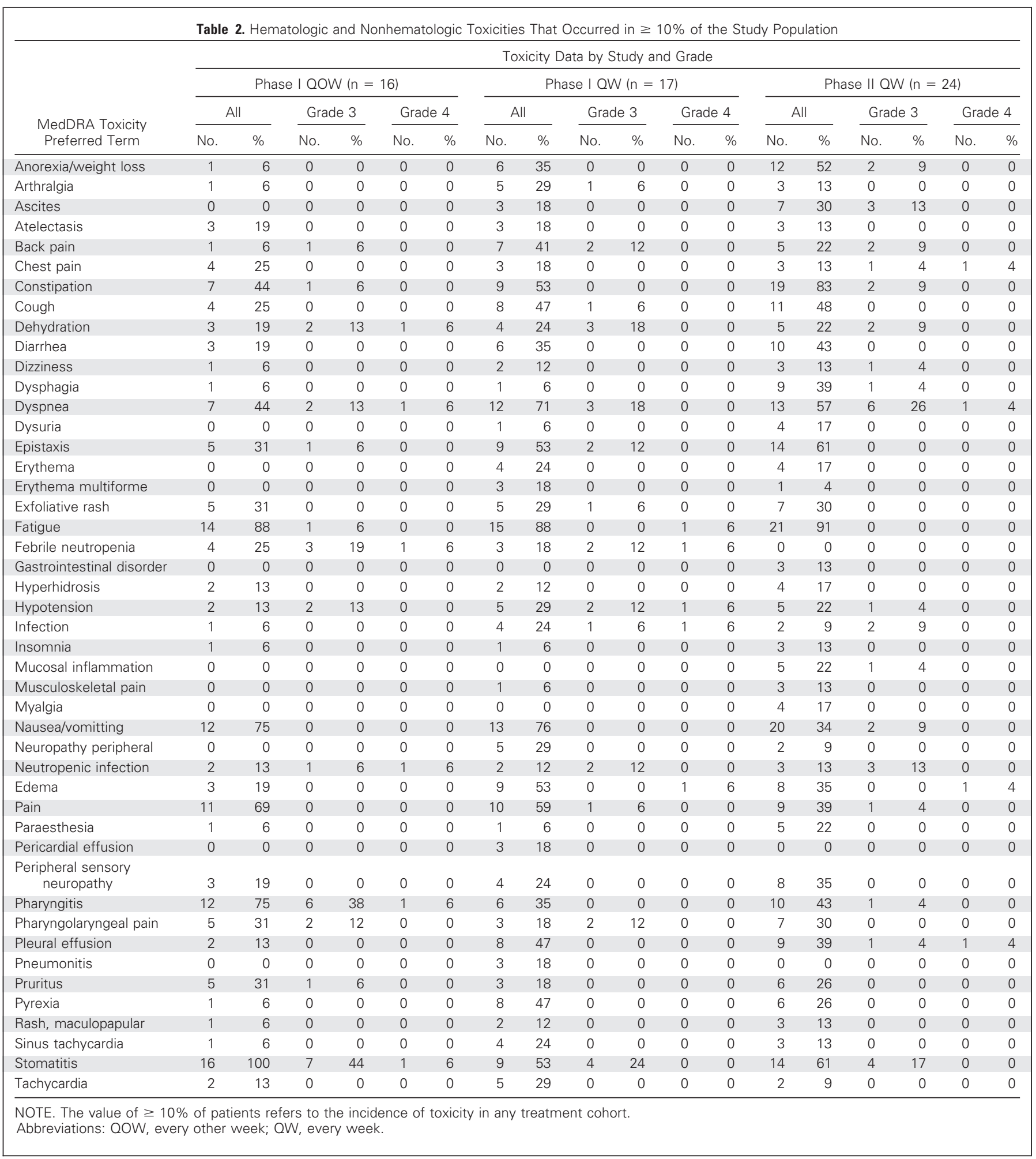


experienced grades 3 or 4 toxicity thereafter received a reduced dose of pralatrexate $100 \mathrm{mg} / \mathrm{m}^{2}$ (ie, approximately $33 \%$ dose reduction). If the patient had no stomatitis (grade 0 ) on folic acid, then the dose could be escalated, but development of any grade 4 stomatitis resulted in removal from study. Patients who developed grade 3 stomatitis on study received folate and vitamin B12 supplementation as described and received a reduced dose of pralatrexate 100 $\mathrm{mg} / \mathrm{m}^{2}$. If the patients experienced no stomatitis on folate and vitamin B12 with pralatrexate $100 \mathrm{mg} / \mathrm{m}^{2}$, then the pralatrexate dose could be escalated back to $135 \mathrm{mg} / \mathrm{m}^{2}$. Any grades 2 or 3 stomatitis thereafter resulted in a pralatrexate dose reduction back to $100 \mathrm{mg} / \mathrm{m}^{2}$. If the patients developed grade 1 stomatitis with the vitamin repletion and dose reduction, they were maintained at the lower dose level and were continued on the vitamins. Patients who developed any grade 4 stomatitis received vitamin supplementation and were removed from study.

Patients who developed any non-stomatitis-based toxicity were assessed according to the following criteria: Patients who developed grades 2 to 3 toxicity during treatment could be treated with a repeat cycle of pralatrexate at a lower dose of $120 \mathrm{mg} / \mathrm{m}^{2}$. Should continued grades 2 to 3 toxicity persist, an additional dose reduction to $100 \mathrm{mg} / \mathrm{m}^{2}$ was allowed. If the patient continued to experience any grades 2 to 3 toxicity after the second dose reduction, the patient was removed from study at that time. Patients who develop any grade 4 toxicities were removed from study.

\section{Response Criteria}

Response criteria followed the guidelines previously reported by Cheson et al. ${ }^{13,14}$ Optional positron emission tomography (PET) scans were performed on virtually all patients pre- and post-treatment. All patients were evaluable for toxicity, and patients evaluable for response were required to have received at least one cycle of therapy (ie, 4 weeks in the QOW phase II study or 7 weeks in the QW phase I/II studies). Response criteria for patients with chronic lymphocytic leukemia or primary leukemic disease were according to the National Cancer Institute guidelines reported by Cheson et al. ${ }^{14}$

\section{RESULTS}

Table 1 lists the general demographic data for all patients enrolled on study. In total, 57 patients were registered on the study, and 41 of these patients were treated on the weekly schedule. The majority of patients (60\%) were men. Overall, the study was comprised of patients with diffuse large B-cell lymphoma, T-cell lymphoma, and HL.

Overall, pralatrexate was better tolerated on the phase II QW schedule. Among the 24 patients treated on this schedule, a total of 46 cycles (ie, 280 doses) were administered. The median number of cycles administered was 1.5 , and 11 patients (43\%) received more than 1.5 cycles. Similarly, the median number of doses administered was nine, and $48 \%$ of patients received more than nine total doses of pralatrexate. Among those patients who received more than nine doses of pralatrexate on the QW schedule, the ORR was $72 \%$. Although this number represents a selection of patients inclined to do better, it also may suggest that those patients able to tolerate protracted dosing have a higher probability of benefit.

Eighteen $(75 \%)$ of 24 patients completed more than one cycle of therapy on the QW phase II schedule. Three (16\%) of these patients missed one dose, four patients (22\%) missed two doses, and three patients missed two doses. Two patients missed more than three doses. The most common reasons for missed doses included grade 3 thrombocytopenia (ie, platelet count 25,000 to 50,000/ $\mu \mathrm{L}$ ) and grades 1 to 2 stomatitis, fatigue, infection, and neutropenia. One patient each experienced a bowel obstruction and odynophagia. Dose reductions to 15 $\mathrm{mg} / \mathrm{m}^{2}$ were invoked for three patients with persistent thrombocytopenia and stomatitis.

\begin{tabular}{|c|c|c|c|c|c|c|c|c|c|c|c|c|c|c|c|c|c|c|}
\hline \multirow[b]{4}{*}{ Laboratory CTC Toxicity } & \multicolumn{18}{|c|}{ Toxicity by Study and Grade } \\
\hline & \multicolumn{6}{|c|}{ Phase I QOW (n = 16) } & \multicolumn{6}{|c|}{ Phase I OW (n=17) } & \multicolumn{6}{|c|}{ Phase II QW (n = 23) } \\
\hline & \multicolumn{2}{|c|}{ All } & \multicolumn{2}{|c|}{ Grade 3} & \multicolumn{2}{|c|}{ Grade 4} & \multicolumn{2}{|c|}{ All } & \multicolumn{2}{|c|}{ Grade 3} & \multicolumn{2}{|c|}{ Grade 4} & \multicolumn{2}{|c|}{ All } & \multicolumn{2}{|c|}{ Grade 3} & \multicolumn{2}{|c|}{ Grade 4} \\
\hline & No. & $\%$ & No. & $\%$ & No. & $\%$ & No. & $\%$ & No. & $\%$ & No. & $\%$ & No. & $\%$ & No. & $\%$ & No. & $\%$ \\
\hline$\overline{A L T}, I U / L H$ & 3 & 19 & 1 & 6 & 0 & 0 & 14 & 82 & 3 & 18 & 0 & 0 & 18 & 78 & 2 & 9 & 0 & $\overline{0}$ \\
\hline AST, IU/L H & 11 & 69 & 1 & 6 & 0 & 0 & 14 & 82 & 1 & 6 & 0 & 0 & 17 & 74 & 0 & 0 & 0 & 0 \\
\hline Albumin, g/dL L & 11 & 69 & 0 & 0 & 0 & 0 & 16 & 94 & 0 & 0 & 0 & 0 & 17 & 74 & 2 & 9 & 0 & 0 \\
\hline Alkaline phosphatase, IU/L H & 12 & 75 & 1 & 6 & 0 & 0 & 13 & 76 & 0 & 0 & 0 & 0 & 17 & 74 & 2 & 9 & 0 & 0 \\
\hline Total bilirubin, mg/dL H & 10 & 63 & 1 & 6 & 0 & 0 & 10 & 59 & 1 & 6 & 1 & 6 & 11 & 48 & 3 & 13 & 0 & 0 \\
\hline Calcium, mg/dL H & 1 & 6 & 1 & 6 & 0 & 0 & 2 & 12 & 0 & 0 & 0 & 0 & 2 & 9 & 0 & 0 & 0 & 0 \\
\hline Calcium, mg/dL L & 8 & 50 & 0 & 0 & 0 & 0 & 14 & 82 & 1 & 6 & 0 & 0 & 16 & 70 & 1 & 4 & 2 & 9 \\
\hline Creatinine, mg/dL H & 6 & 38 & 1 & 6 & 0 & 0 & 4 & 24 & 1 & 6 & 0 & 0 & 9 & 39 & 0 & 0 & 0 & 0 \\
\hline Glucose, mg/dL H & 12 & 75 & 1 & 6 & 0 & 0 & 16 & 94 & 4 & 24 & 0 & 0 & 22 & 96 & 4 & 17 & 0 & 0 \\
\hline Glucose, mg/dL L & 3 & 19 & 0 & 0 & 0 & 0 & 5 & 29 & 2 & 12 & 0 & 0 & 6 & 26 & 0 & 0 & 0 & 0 \\
\hline Hemoglobin, g/dL L & 16 & 100 & 5 & 31 & 3 & 19 & 17 & 100 & 6 & 35 & 1 & 6 & 21 & 91 & 7 & 30 & 2 & 9 \\
\hline Lymphocytes, cells/ $\mu \mathrm{L}$ & 14 & 88 & 4 & 25 & 7 & 44 & 14 & 82 & 6 & 35 & 5 & 29 & 19 & 83 & 11 & 48 & 5 & 22 \\
\hline Magnesium, mEq/L H & 3 & 19 & 0 & 0 & 0 & 0 & 3 & 18 & 0 & 0 & 0 & 0 & 1 & 4 & 0 & 0 & 0 & 0 \\
\hline Magnesium, mEq/L L & 6 & 38 & 1 & 6 & 0 & 0 & 6 & 35 & 0 & 0 & 0 & 0 & 5 & 22 & 1 & 4 & 0 & 0 \\
\hline Neutrophils, cells/ $\mu \mathrm{L}$ & 11 & 69 & 3 & 19 & 6 & 38 & 11 & 65 & 2 & 12 & 6 & 35 & 11 & 48 & 5 & 22 & 4 & 17 \\
\hline PTT, seconds $\mathrm{H}$ & 8 & 50 & 3 & 19 & 0 & 0 & 10 & 59 & 1 & 6 & 0 & 0 & 12 & 52 & 3 & 13 & 0 & 0 \\
\hline Platelet count, cells $/ \mu \mathrm{L}$ & 13 & 81 & 2 & 13 & 6 & 38 & 15 & 88 & 4 & 24 & 8 & 47 & 18 & 78 & 4 & 17 & 7 & 30 \\
\hline Potassium, mEq/L H & 1 & 6 & 0 & 0 & 0 & 0 & 2 & 12 & 1 & 6 & 0 & 0 & 2 & 9 & 1 & 4 & 0 & 0 \\
\hline Potassium, mEq/L L & 16 & 100 & 2 & 13 & 0 & 0 & 17 & 100 & 4 & 24 & 0 & 0 & 23 & 100 & 4 & 17 & 0 & 0 \\
\hline Sodium, mEq/L H & 5 & 31 & 0 & 0 & 0 & 0 & 9 & 53 & 0 & 0 & 0 & 0 & 11 & 48 & 0 & 0 & 0 & 0 \\
\hline Sodium, mEq/L L & 8 & 50 & 1 & 6 & 0 & 0 & 9 & 53 & 2 & 12 & 0 & 0 & 9 & 39 & 2 & 9 & 0 & 0 \\
\hline White blood cells & 12 & 75 & 5 & 31 & 5 & 31 & 14 & 82 & 6 & 35 & 2 & 12 & 17 & 74 & 1 & 4 & 6 & 26 \\
\hline
\end{tabular}

NOTE. The value of $\geq 10 \%$ of patients refers to the incidence of toxicity in any treatment cohort.

Abbreviations: CTC, Common Toxicity Criteria; H, high; L, low; QOW, every other week; OW, every week; PTT, prothrombin time. 
Tables 2 and 3 list the grades 3 to 4 toxicities that occurred in greater than $10 \%$ of the study population. On the QOW phase II study, the major toxicity was stomatitis, which occurred in some form in virtually all patients; eight patients (54\%) experienced grade 3 or 4 stomatitis events. Events of pharyngitis, pharyngolaryngeal, pain, nausea, and vomiting were all stomatitis related. Other grades 3 or 4 events included leukopenia (62\%), lymphopenia (69\%), and thrombocytopenia (51\%). Conversion from a QOW to QW schedule resulted in a significant reduction of grades 3 to 4 toxicity: stomatitis decreased from $54 \%$ to $17 \%$; pharyngitis decreased from $44 \%$ to $4 \%$, leukopenia decreased from $62 \%$ to $30 \%$, and lymphopenia remained essentially constant. Most of the toxicities on the QW schedule were experienced by patients treated at the MAD of $45 \mathrm{mg} / \mathrm{m}^{2}$ (ie, 11 of these 17 patients).

The MAD was $45 \mathrm{mg} / \mathrm{m}^{2}$ weekly for 6 of 7 weeks. At this dose, cycle 1 DLTs included neutropenic fever $(n=1)$; neutropenia $(n=1)$; and missed doses $(\mathrm{n}=1)$, for which three $(\mathrm{n}=1$ for low platelets; $\mathrm{n}=$ 2 for stomatitis) of six planned doses were missed. In addition, three patients missed two of six doses, mostly for neutropenia and thrombocytopenia, although this was not defined as a DLT. Two grade 5 toxicities occurred. One patient with adult T-cell leukemia/lymphoma and one patient with enteropathy-associated T-cell lymphoma died as a result of sepsis associated with rapid reduction in tumor that led to open skin wounds and bowel perforation, respectively. Both of these events were attributed to a compromise of anatomic barriers that led to life-threatening infections. Because of these events, the dose cohort was expanded to 12 patients $(n=11$ treated) after attaining institutional review board approval. There were no additional DLTs in the remainder of the cohort. Given the spectrum of toxicity and the missed doses, this dose level was declared the MAD.

Tables 4 and 5 list the response data. The only patient with T-cell disease who was treated on the QOW schedule experienced a PETnegative CR after one dose of pralatrexate, and all other patients experienced essentially stable disease. Overall, nine patients were not evaluable: three for marked progression of disease after one dose of drug; two for mucositis (both in the QOW arm); two who developed sepsis after partial resolution of bowel and skin disease; one for thrombocytopenia; and one as a result of myocardial infarction unrelated to pralatrexate. After conversion to the QW schedule, two $(n=1$ T acute lymphoblastic leukemia/lymphoma; $\mathrm{n}=1$ adult T-cell leukemia/ lymphoma) of three patients who were treated at the first dose cohort (ie, $30 \mathrm{mg} / \mathrm{m}^{2}$ each week for 3 of 4 weeks) achieved PR, as did a patient with $\gamma, \delta$-subcutaneous panniculitis-like T-cell lymphoma who was treated at the next-highest dose level (ie, $30 \mathrm{mg} / \mathrm{m}^{2}$ each week for 6 of 7 weeks). The ORR was 31\% (in all patients), which included eight patients who experienced CR and seven who experienced PR. All patients with HL $(n=8)$ achieved only stable disease. Only one $(5 \%)$ of 20 patients with B-cell lymphoma responded, and $54 \%$ of patients with T-cell lymphoma attained a major remission. Of those patients who responded, eight (31\%) experienced CR, and six (23\%) experienced PR. Four of the six who experienced PR were PET negative.

Table 6 lists the patients who responded and the duration of response. These data suggest that despite refractory disease, pralatrexate is capable of inducing durable remissions, as eight patients (53\%) had at least a 6-month remission, and four patients experienced sustained remission for a year or more. Interestingly, two patients (patients 2 and 4) had prior MTX treatment. Patient 2 relapsed months after ending an MTX-based maintenance program, whereas patient 4 was refractory to MTX immediately before receiving pralatrexate. These modest experiences suggest a lack of cross resistance between MTX and pralatrexate.

\section{DISCUSSION}

RFC is a unique therapeutic target. Its restricted expression on malignant and fetal tissues gives it the potential for a significant therapeutic index. Although pralatrexate was structurally modeled after MTX, it is clear that the spectrum of activity seen in these study patients is unusual. Although it is difficult to define well-established, single-agent response rates for MTX within our present nomenclature of lymphoma, some studies give insight into the activity of MTX in this patient population. One report documented six patients who experienced CR and five who experienced PR of 22 patients treated for predominantly B-cell NHL with escalating doses of MTX and leucovorin. ${ }^{15}$ In another study, 20 patients with advanced B-cell NHL were treated with high-dose MTX plus leucovorin. ${ }^{16}$ Although the ORR in this study was $60 \%$, the CR rate was approximately $20 \%$. Though the

\begin{tabular}{|c|c|c|c|c|c|c|c|c|c|c|c|c|c|c|c|c|c|c|}
\hline \multirow{4}{*}{$\begin{array}{l}\text { Response } \\
\text { Type }\end{array}$} & \multicolumn{18}{|c|}{ Study Design } \\
\hline & \multicolumn{6}{|c|}{ Phase II QOW } & \multicolumn{6}{|c|}{ Phase I OW } & \multicolumn{6}{|c|}{ Phase II OW } \\
\hline & \multicolumn{2}{|c|}{$\begin{array}{c}\text { All } \\
(n=13 / 16)\end{array}$} & \multicolumn{2}{|c|}{$\begin{array}{c}\text { B Cell/HD } \\
(n=12 / 15)\end{array}$} & \multicolumn{2}{|c|}{$\begin{array}{c}\text { T Cell } \\
(n=1)\end{array}$} & \multicolumn{2}{|c|}{$\begin{array}{c}\text { All } \\
(n=14 / 17)\end{array}$} & \multicolumn{2}{|c|}{$\begin{array}{c}\text { B Cell/HD } \\
(n=5 / 6)\end{array}$} & \multicolumn{2}{|c|}{$\begin{array}{c}\text { T Cell } \\
(n=9 / 11)\end{array}$} & \multicolumn{2}{|c|}{$\begin{array}{c}\text { All } \\
(n=21 / 24)\end{array}$} & \multicolumn{2}{|c|}{$\begin{array}{l}\text { B Cell/HD } \\
(n=3 / 4)\end{array}$} & \multicolumn{2}{|c|}{$\begin{array}{c}\text { T Cell } \\
(n=16 / 18)\end{array}$} \\
\hline & No. & $\%$ & No. & $\%$ & No. & $\%$ & No. & $\%$ & No. & $\%$ & No. & $\%$ & No. & $\%$ & No. & $\%$ & No. & $\%$ \\
\hline CR/Cru & 1 & 8 & 0 & 0 & 1 & 100 & 4 & 29 & 0 & 0 & 4 & 44 & 3 & 14 & 0 & 0 & 3 & 19 \\
\hline PR & 0 & 0 & 0 & 0 & 0 & 0 & 2 & 14 & 1 & 20 & $1^{*}$ & 11 & 5 & 24 & 0 & 0 & $5+$ & 31 \\
\hline SD & 10 & 77 & 10 & 83 & 0 & 0 & 3 & 21 & 3 & 60 & 0 & 0 & 4 & 19 & 2 & 66 & 2 & 13 \\
\hline NE & 3 & 23 & 3 & 25 & 0 & 0 & 3 & 21 & 1 & 20 & 2 & 22 & 3 & 14 & 1 & 33 & 2 & 13 \\
\hline POD & 2 & 15 & 2 & 17 & 0 & 0 & 5 & 36 & 1 & 20 & 4 & 44 & 9 & 43 & 1 & 33 & 6 & 38 \\
\hline \multicolumn{19}{|c|}{$\begin{array}{l}\text { NOTE. Data were based on evaluable patients. Two patients with composite lymphoma (T-and B-cell non-Hodgkin's lymphoma) had progression of disease and } \\
\text { therefore could not be additionally subclassified strictly as B- or T-cell non-Hodgkin's lymphoma. } \\
\text { Abbreviations: QOW, every other week; OW, every week; HD, Hodgkin's disease; CR, complete remission; CRu, unconfirmed complete remission; PR, partial } \\
\text { remission; SD, stable disease; NE, not evaluable; POD, progression of disease. } \\
\text { "Negative positron emission tomography in one patient. } \\
\text { †Negative positron emission tomography in three patients. }\end{array}$} \\
\hline
\end{tabular}




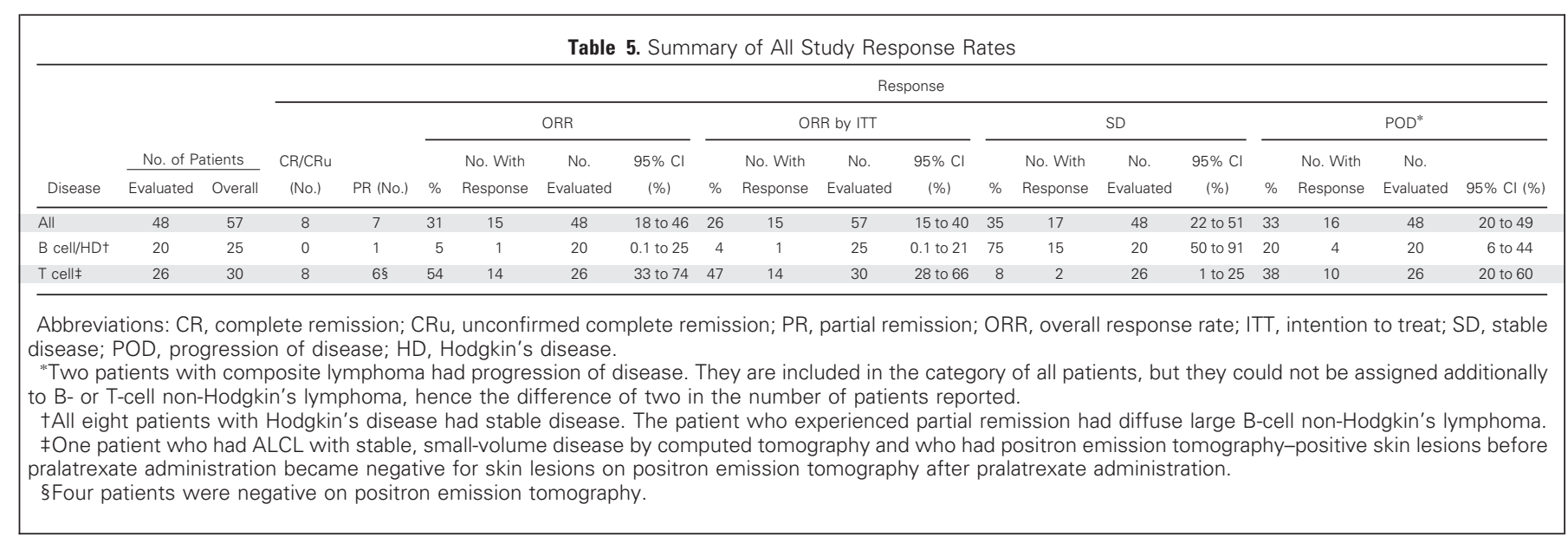

remissions in each of these instances were not durable, the initial cytoreduction was considered significant and helped establish the activity of MTX for lymphoma.

The activity of pralatrexate in T-cell lymphoma is impressive for a disease without effective standard therapies. The activity in T-cell lymphoma is interesting because it also occurred at low doses, which is likely attributable to the significantly higher affinity of pralatrexate for RFC. The modest activity in B-cell NHL or HL does not suggest that pralatrexate is inactive in B-cell NHL, but suggests that other schedules need to be explored. A feature of the QOW schedule was cytokinetic failures, as many patients with B-cell disease exhibited prompt but transient clinical responses during the first week after treatment. The mucositis was preempted by using pralatrexate QW at those doses initially. The observation that modulation of Hcy and MMA with folic acid and vitamin B12 could abrogate stomatitis has shifted the conduct of all ongoing pralatrexate studies. In fact, two patients with low baseline Hcy and MMA who had both undergone previous tandem peripheral-blood stem-cell transplantations tolerated pralatrexate 240 $\mathrm{mg} / \mathrm{m}^{2}$ QOW. These insights have now led to new phase I studies in solid tumor malignancies in which vitamin repletion has increased the QOW MTD to $270 \mathrm{mg} / \mathrm{m}^{2}{ }^{2}$. The supplementation of vitamins with pralatrexate of course raises concerns about the risk of compromising the benefit of the drug, which does not seem to be borne out in laboratory studies or in this study, at least in T-cell NHL.

The importance of the population PK and nutritional covariates has been analyzed in a population-based PK model. Early data from Mould et al ${ }^{18}$ suggest that the two most significant determinants of stomatitis risk are pretreatment MMA and area under the

\begin{tabular}{|c|c|c|c|c|c|}
\hline \multirow[b]{2}{*}{ Patient } & \multirow[b]{2}{*}{ Disease } & \multicolumn{2}{|c|}{ Pralatrexate Response Data } & \multirow{2}{*}{$\begin{array}{l}\text { Duration of Response to } \\
\text { Prior Therapy (months) }\end{array}$} & \multirow{2}{*}{$\begin{array}{l}\text { Duration of Response to } \\
\text { Pralatrexate (months) }\end{array}$} \\
\hline & & Response Type & Study Type & & \\
\hline 1 & PTCL NOS & CR & Phase II QOW & Refractory & 3 \\
\hline 2 & T-cell ALL & CR & Phase I OW & 7 & 12 \\
\hline 3 & HTLV-1 ATLL & CR & Phase I OW & Refractory & 26 \\
\hline 4 & $\gamma, \delta$-SQ paniculitis-like T cell & CR & Phase I OW & Refractory & $9^{*}$ \\
\hline 5 & ALCL (ALK positive) & CR & Phase I OW & $48 t$ & $\geq 22$ \\
\hline 6 & Diffuse large B-cell NHL & PR & Phase I OW & 14 & 1.5 \\
\hline 7 & Blastic NK/T & PET-negative CR & Phase I OW & Refractory & 6 \\
\hline 8 & ALCL (ALK negative) & $\mathrm{CRu}$ & Phase II OW & 8 & 2 \\
\hline 9 & PTCL NOS & CR & Phase II OW & 4 & $12 \ddagger$ \\
\hline 10 & Subcutaneous paniculitis-like $\mathrm{T}$ cell & CR & Phase II OW & Refractory & $10^{*}$ \\
\hline 11 & Angioimmunoblastic T-cell lymphoma & PET-negative SD by CT & Phase II OW & Refractory & 3 \\
\hline 12 & Mycosis fungoides & PR & Phase II OW & Refractory & $\geq 2$ \\
\hline 13 & PTCL NOS & PR & Phase II OW & Untreated & 5 \\
\hline 14 & PTCL NOS & PR & Phase II OW & Refractory & $1-2$ \\
\hline 15 & PTCL NOS & PR & Phase II OW & 4 & 6.5 \\
\hline \multicolumn{6}{|c|}{$\begin{array}{l}\text { Abbreviations: PTCL NOS, peripheral T-cell lymphoma not otherwise specified; CR, complete remission; QOW, every other week; ALL, acute lymphoblastic } \\
\text { lymphoma/leukemia; OW, every week; HTLV-1 ATLL, human T-cell lymphotropic virus type } 1 \text { adult T-cell leukemia/lymphoma; SO, subcutaneous; ALCL, anaplastic } \\
\text { large T-cell lymphoma; ALK, anaplastic large-cell kinase; NHL, non-Hodgkin's lymphoma; PR, partial remission; NK/T, natural killer/T cell; PET, positron emission } \\
\text { tomography; CRu, unconfirmed complete remission; SD, stable disease; CT, computed tomography. } \\
\text { *The response was followed by allogeneic transplantation. } \\
\text { †The 4-year response included post-peripheral-blood stem-cell transplantation. } \\
\text { łPatient developed idiopathic immune thrombocytopenia, for which corticosteroids were administered; corticosteroids were followed by splenectomy. He } \\
\text { remained in complete remission at } 24 \text { months, though the initiation of corticosteroids rendered him technically off study. }\end{array}$} \\
\hline
\end{tabular}


curve exposure. These models appear to predict nearly $100 \%$ of the patients who experience stomatitis, though analyses with other specific hematologic toxicities are ongoing. ${ }^{18}$

On the basis of the activity in T-cell malignancies, an international, multicenter, phase II study in peripheral T-cell lymphoma (PROPEL) has been completed, and a phase II study in cutaneous T-cell lymphoma is ongoing. New studies in B-cell lymphoma to explore higher doses on a QOW basis with vitamins are planned. A major emphasis is being placed on understanding the mechanistic basis for the activity in T-versus B-cell lymphoma at a molecular level. These data have established that pralatrexate exhibits marked activity in a diverse spectrum of refractory T-cell malignancies, which produces durable responses in heavily treated patients.

\section{AUTHORS' DISCLOSURES OF POTENTIAL CONFLICTS} OF INTEREST

Although all authors completed the disclosure declaration, the following author(s) indicated a financial or other interest that is relevant to the subject matter under consideration in this article. Certain relationships marked with a "U" are those for which no compensation was received; those relationships marked with a " $C$ " were compensated. For a detailed description of the disclosure categories, or for more information about ASCO's conflict of interest policy, please refer to the Author Disclosure Declaration and the Disclosures of Potential Conflicts of Interest section in Information for Contributors.
Employment or Leadership Position: Mike Saunders, Allos Therapeutics (C) Consultant or Advisory Role: None Stock Ownership: None Honoraria: None Research Funding: Owen A. O'Connor, Allos Therapeutics; Steven Horwitz, Allos Therapeutics Expert Testimony: None Other Remuneration: None

\section{AUTHOR CONTRIBUTIONS}

Conception and design: Owen A. O'Connor, Frank Sirotnak Financial support: Owen A. O'Connor

Administrative support: Owen A. O'Connor, Mike Saunders Provision of study materials or patients: Owen A. O'Connor, Steven Horwitz, Paul Hamlin, Carol Portlock, Craig H. Moskowitz, Ellen Neylon, Barbara MacGregor-Cortelli, Molly Patterson, Martin Fleisher, Andrew D. Zelenetz

Collection and assembly of data: Owen A. O'Connor, Steven Horwitz, Paul Hamlin, Carol Portlock, Debra Sarasohn, Ellen Neylon, Jill Mastrella, Rachel Hamelers, Barbara MacGregor-Cortelli, Molly Patterson, Frank Sirotnak, Martin Fleisher, Diane R. Mould

Data analysis and interpretation: Owen A. O'Connor, Steven Horwitz, Paul Hamlin, Debra Sarasohn, Ellen Neylon, Rachel Hamelers, Molly Patterson, Venkatraman E. Seshan, Frank Sirotnak, Martin Fleisher, Diane R. Mould, Mike Saunders, Andrew D. Zelenetz

Manuscript writing: Owen A. O'Connor

Final approval of manuscript: Owen A. O'Connor, Steven Horwitz, Paul Hamlin, Carol Portlock, Craig H. Moskowitz, Debra Sarasohn, Ellen Neylon, Jill Mastrella, Rachel Hamelers, Barbara MacGregor-Cortelli, Molly Patterson, Venkatraman E. Seshan, Frank Sirotnak, Martin Fleisher, Diane R. Mould, Mike Saunders, Andrew D. Zelenetz

\section{REFERENCES}

1. Kühnel JM, Chiao JH, Sirotnak FM: Contrasting effects of oncogene expression on two carriermediated systems internalizing folate compounds in Fisher rat 3T3 cells. J Cell Physiol 184:364-372, 2000

2. Chiao JH, Roy $\mathrm{K}$, Tolner $B$, et al: RFC-1 gene expression regulates folate absorption in mouse small intestine. J Biol Chem 272:11165-11170, 1997

3. Sirotnak FM, Tolner B: Carrier-mediated membrane transport of folates in mammalian cells. Annu Rev Nutr 19:91-122, 1999

4. Schmid FA, Sirotnak FM, Otter GM, et al: New folate analogs of the 10-deaza-aminopterin series: Markedly increased antitumor activity of the 10-ethyl analog compared to the parent compound and methotrexate against some human tumor xenografts in nude mice. Cancer Treat Rep 69:551-553, 1985

5. Sirotnak FM, DeGraw JI, Moccio DM, et al: New folate analogs of the 10-deaza-aminopterin series: Basis for structural design and biochemical and pharmacologic properties. Cancer Chemother Pharmacol 12:18-25, 1984

6. Sirotnak FM, DeGraw JI, Schmid FA, et al: New folate analogs of the 10-deaza-aminopterin series: Further evidence for markedly increased antitumor efficacy compared with methotrexate in ascitic and solid murine tumor models. Cancer Chemother Pharmacol 12:26-30, 1984
7. Sirotnak FM, Schmid FA, Samuels LL, et al: 10-Ethyl-10-deaza-aminopterin: Structural design and biochemical, pharmacologic, and antitumor properties. NCl Monogr 127-131, 1987

8. Sirotnak FM, DeGraw JI, Colwell WT, et al: A new analogue of 10-deazaaminopterin with markedly enhanced curative effects against human tumor xenografts in mice. Cancer Chemother Pharmacol 42:313-318, 1998

9. Wang ES, O'Connor $O$, She $Y$, et al: Activity of a novel anti-folate (PDX, 10-propargyl 10deazaaminopterin) against human lymphoma is superior to methotrexate and correlates with tumor RFC-1 gene expression. Leuk Lymphoma 44:10271035, 2003

10. Toner LE, Vrhovac R, Smith EA, et al: The schedule-dependent effects of the novel antifolate pralatrexate and gemcitabine are superior to methotrexate and cytarabine in models of human nonHodgkin's lymphoma. Clin Cancer Res 12:924-932, 2006

11. Krug LM, Ng KK, Kris MG, et al: Phase I and pharmacokinetic study of 10-propargyl-10deazaaminopterin, a new antifolate. Clin Cancer Res 6:3493-3498, 2000

12. Krug LM, Azzoli CG, Kris MG, et al: 10-propargy10-deazaaminopterin: An antifolate with activity in patients with previously treated non-small-cell lung cancer. Clin Cancer Res 9:2072-2078, 2003
13. Cheson BD, Horning SJ, Coiffier B, et al: Report of an international workshop to standardize response criteria for non-Hodgkin's lymphomas: $\mathrm{NCl}-S p o n s o r e d$ International Working Group. J Clin Oncol 17:1244, 1999

14. Cheson BD, Bennett JM, Grever M, et al: National Cancer Institute-sponsored Working Group guidelines for chronic lymphocytic leukemia: Revised guidelines for diagnosis and treatment. Blood 87:4990-4997, 1996

15. Djerassi I, Kim JS: Methotrexate and citrovorum factor rescue in the management of childhood lymphosarcoma and reticulum cell sarcoma (nonHodgkin's lymphomas): Prolonged unmaintained remissions. Cancer 38:1043-1051, 1976

16. Skarin AT, Zuckerman KS, Pitman SW, et al: High-dose methotrexate with folinic acid in the treatment of advanced non-Hodgkin's lymphoma including CNS involvement. Blood 50:1039-1047, 1977

17. Azzoli CG, Krug L, Miller V, et al: Phase I study of the antifolate pralatrexate given with vitamin B12 and folic acid supplementation in patients (pts) with advanced non-small-cell lung cancer. J Clin Oncol 25:608s, 2007 (suppl; abstr 13006)

18. Mould DR, Sweeney, Kevin, Duffull, Stephen, Neylon, Ellen, O'Connor, Owen A: A Population Pharmacokinetic and Pharmacodynamic Evaluation of Pralatrexate in Patients with Hematologic Malignancies. Clin Pharmacol Ther [e-pub ahead of print May 27, 2009] 